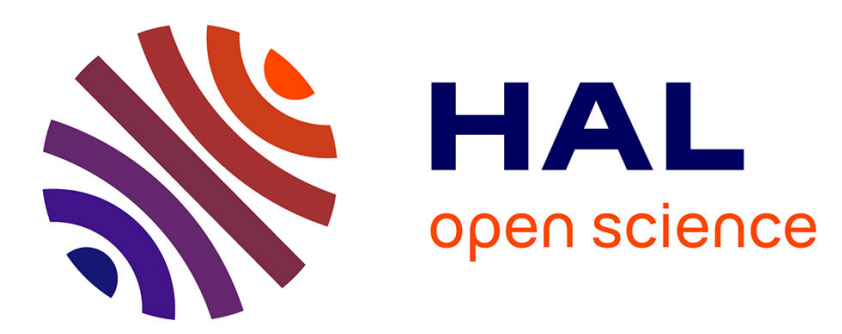

\title{
Strain Localisation in iPP/MWCNT Nanocomposites Using Digital Image Correlation
}

\author{
E. Ivanov, P. Ienny, Romain Léger, A. S. Caro-Bretelle, R. Kotsilkova
}

\section{To cite this version:}

E. Ivanov, P. Ienny, Romain Léger, A. S. Caro-Bretelle, R. Kotsilkova. Strain Localisation in iPP/MWCNT Nanocomposites Using Digital Image Correlation. Strain, 2014, 50 (1), pp.37 - 47. 10.1111/str.12065 . hal-01793552

HAL Id: hal-01793552

\section{https://hal.science/hal-01793552}

Submitted on 16 May 2018

HAL is a multi-disciplinary open access archive for the deposit and dissemination of scientific research documents, whether they are published or not. The documents may come from teaching and research institutions in France or abroad, or from public or private research centers.
L'archive ouverte pluridisciplinaire HAL, est destinée au dépôt et à la diffusion de documents scientifiques de niveau recherche, publiés ou non, émanant des établissements d'enseignement et de recherche français ou étrangers, des laboratoires publics ou privés. 


\title{
Strain localization in iPP/MWCNT nanocomposites using digital image correlation
}

\author{
E. Ivanov ${ }^{a}$, P. Ienny ${ }^{b}$, R. Leger ${ }^{b}$, A.S. Caro-Bretelle ${ }^{b^{*}}$, R. Kotsilkova ${ }^{a}$ \\ ${ }^{a}$ Institute of Mechanics, Bulgarian Academy of Sciences, Acad. G. Bonchev St., Block 1, 1113 Sofia, Bulgaria \\ ${ }^{\mathrm{b}}$ Centre des Matériaux des Mines d'Alès, Ecole des Mines d'Alès, 6 avenue de Clavières, F-30319 Alès Cedex, \\ France
}

This article has been first published in STRAIN in October 21, 2013. https://doi.org/10.1111/str.12065

\begin{abstract}
Polypropylene/multiwall carbon nanotubes nanocomposites with different rate of weight incorporation $(0$ to $1 \%$ ) were prepared by melt compounding and cast extrusion. The effect of maleic anhydride (5wt\%) grafted on polypropylene is study through mechanical tests at different scales and morphological observations. In particular, the micromechanism of deformation was investigated through instrumented tensile experiments (at a macro and micro scale) using of a non-contact method known as Digital Image Correlation. The objective of this paper is first to characterize global behaviour (Young modulus, tensile strength, ultimate properties) and second to go further in local analysis. In particular optical instrumentation enables estimation of strain profile distribution onto the sample in a strictioned area. Statistical parameters extracted from these local profiles are promising tools to enhance mechanical properties in link with microstructural composition. Tensile tests confirm composites reinforcement at a low level of nanocomposites incorporation and local analysis enables quantitative measurements of adding maleic anhydride in formulations. The results reveal that addition of maleic anhydride delays strain localization in the strictioned area.
\end{abstract}

Keywords: Polymer nanocomposites; polypropylene; multiwall carbon nanotubes; micro mechanism of deformation; digital image correlation; ultimate properties; striction

\section{Introduction}

Polymer nanocomposites filled up with carbon nanotubes (CNTs) gained intensive interest thanks to their unique and valuable mechanical, thermal, and electrical properties compared to the virgin polymers [1-10]. One of the CNTs advantages as a reinforcement filler is their large surface area that can induce a better adhesion with the polymer matrix, which is an important factor for an effective enhancement of the composite properties.

However, in order to take advantage of the unique properties of CNTs, the main challenge is to improve the dispersion and distribution of CNTs within the polymer matrix, CNTs having tendency to form agglomerates. This is due to the strong intermolecular Van der Waals interactions among the CNTs in combination with their high surface area and high aspect ratio. In the polymer composite, these agglomerates decrease the surface area, disturb the formation of the polymer network and are responsible for low mechanical properties. That is why the main task of processing is to dissolve such agglomerates as much as possible. Therefore, uniform dispersion of the CNT is required to realize the potentiality of the nanotubes as reinforcing fillers [11-17].

The methods for preparation of polymer nanocomposites filled with CNTs are in situ polymerization, solution mixing and melt blending. Extrusion process is frequently used due to its industrial importance and ability to disperse CNTs in the matrix. From all polymer matrices, polypropylene (PP) is one of the widely used thermoplastic polymers for industry like automotive and food packaging for its low cost and well-balanced mechanical and physical

*Corresponding author

Anne-Sophie.Caro@mines-ales.fr

Tel: $+33(0) 466785631$

Fax: $+33(0) 466785680$ 
properties as well. Other authors recently reported their findings on polymer chains grafted onto CNTs showing that they allow reducing the aggregation of nanotubes and improving the homogeneous dispersion in the matrix, and finally leading to the increase of the mechanical properties due to load transfer between matrix and nanotubes [18-21].

There are many studies in the literature on the macromechanical properties of the polymer nanocomposites filled with nanoparticles but there are very limited information about micro and nanomechanical properties and micromechanism of deformation [22]. At nanoscale level the mechanics of the materials is different and interfacial interactions play an important role. One of the non-contact measurement techniques in the experimental mechanics is the Digital Image Correlation (DIC). The DIC method has been widely accepted and used as a powerful and flexible tool for the surface deformation measurement in the field of experimental solid mechanics. It directly provides full-field displacements and strains by comparing the digital images of the specimen surface in the un-deformed (chosen as the reference state) and deformed states, respectively. In principle, DIC is an optical metrology based on digital image processing and numerical computing [23-25].

The main objective of the present work is to investigate the effect of multiwall carbon nanotube (MWCNT) concentration and MWCNT concentration at $5 \mathrm{wt} \%$ of maleic anhydride (MA) in isotactic polypropylene (iPP) on the micro mechanism of deformation of iPP/MWCNT nanocomposites based on tensile experiments and DIC. It is well known that the grafted maleic anhydride groups will form chemical or hydrogen bonding with the CNTs, improving the interfacial adhesion between CNTs and iPP matrix. This compatibilizer therefore acts as a coupling agent to enhance homogeneous dispersion percolated network structure of CNTs in the PP matrix [26].

\section{Experimental study}

\subsection{Materials used and fabrication of nanocomposites}

A masterbatch of $20 \mathrm{wt} \%$ MWCNT in PP was obtained in pellet form from Hyperion Catalysis International, USA. MWCNTs are commercially manufactured from high purity, low molecular weight hydrocarbons in a continuous, gas phase, catalyzed reaction. Typical outside diameter range of the tubes is from 10 to $15 \mathrm{~nm}$, the lengths are between 1 and 10 microns, and their density is approximately $1.75 \mathrm{~g} / \mathrm{cm}^{3}$. The masterbatch is produced by initially dispersing intertwined agglomerates of nanotubes into the polymer.

iPP homopolymer "Buplen" 6231 with density $\rho=0.901 \mathrm{~g} / \mathrm{cm}^{3}$ and melt flow index MFI (230/2.16) of $12.2 \mathrm{~g} / 10 \mathrm{~min}$, supplied by Lukoil Neftochim Co., Bulgaria, was used as the matrix polymer. Maleic anhydride grafted polypropylene (MA-g-PP) Licomont AR 504, product of Clariant $\mathrm{GmbH}$, Germany, was used as a chemical compatibiliser for improving the interaction between the polymer matrix and MWCNTs and the wetting of MWCNT particles as well.

Nanocomposites were produced by direct melt compounding in Brabender DSE 35/17D twin screw extruder according to a two steps process. First, the masterbatch was diluted to different CNT concentrations in the range of 0.05 to $1 \mathrm{wt} \% \mathrm{CNT}$ with neat iPP at melt temperature of $200{ }^{\circ} \mathrm{C}$ and a screw speed of $30 \mathrm{rpm}$. The extruded composites were cooled and pelletized. In order to improve the CNT dispersion, these compositions were extruded a second time. MA-g-PP (5\% wt) was added into the nanocomposites during a second stage and 
pelletized. The compound is then calendered as sheets of various thicknesses ( 0.4 to $1 \mathrm{~mm})$ at melt temperature of $230{ }^{\circ} \mathrm{C}$ and a screw speed of $30 \mathrm{rpm}$.

\subsection{Characterization of composites}

\subsubsection{Microstructure}

Optical microscope has been used to investigate the quality of the MWCNTs distribution and dispersion in the matrix. Strips of $1 \mathrm{~mm}$ thick have been cryo-fractured and observed. First of all neat and maleic iPP are characterized. Optical micrographs (Figs. 1) reveals large spherulites with diameter of $100 \mu \mathrm{m}$ and small spherulites of about $50 \mu \mathrm{m}$ for the neat iPP (Fig. 1a); addition of MA produces a non-homogeneous structure ranging from large spherulites of $200 \mu \mathrm{m}$ to a mixture of large and small spherulites from 10 to $100 \mu \mathrm{m}$ (Fig. 1b, c, d). The agglomeration of nanotubes in the nanocomposites has been also studied through this optical device (Figs. 2). CNTs aggregates are observed as dark spots with a broad particle size distribution (smaller to bigger as the CNTs concentration increases [40]). At these levels of incorporation, aggregates are well dispersed. After $0.5 \mathrm{wt} \% \mathrm{CNTs}$, we observe a non-homogeneous structure with nondispersed aggregates smaller for the formulation with MA (Fig. 3). At a higher level of CNTs incorporation (Figs. 4) micrographs reveal non-homogeneous structure with non-dispersed aggregates of the masterbatch (smaller for the formulation with MA).

\subsubsection{Standard tensile test instrumented by DIC}

Tensile properties (uniaxial tensile test) were determined by using ZWICK TH010 universal testing machine equipped with a high resolution Charge-Coupled Device (CCD) camera (Redlake Megaplus II) with a telecentric lens of focal length of 55mm adapted for DIC and a load cell of $0.5 \mathrm{kN}$. Wedge grip were used for clamping the samples.

The camera is fixed on a Newport Motion Controller Model ESP301. Such equipment is very useful in case of large strains in order to follow the region of interest (ROI) at the center of the sample and remove the rigid body motion. The optical axis of the camera is perfectly perpendicular to the surface of the specimen. Acquisition of images (1920x1080 pixels, 256 grey levels) is performed by LabVIEW® software which allows the simultaneous acquisition of images and data provided by testing machine (such as load and crosshead displacement). According to the test speed of $10 \mathrm{~mm} / \mathrm{min}, 2$ images were recorded every second. The scale factor or magnification $(\mathrm{k})$ which depends on the lens focal and the distance between camera and object was fixed to $32 \mu \mathrm{m}$ per pixel. This scale factor constitutes a compromise between a necessary spatial resolution for the local strain measurements and the limitation of the perspective errors associated to the out of plane displacement [27].

As far as local analysis is concerned, expected samples were machined with a curved profile so that the neck initiation takes place within the observation field of the camera (Fig. 5a). This observed zone corresponds to the minimal section $(4 \mathrm{~mm})$ of the specimen. A radius curvature of $42.5 \mathrm{~mm}$ is used to keep the tensile load uniaxial and limit heterogeneities. The specimen thickness is between $0.4 \mathrm{~mm}$ and $1 \mathrm{~mm}$.

A speckle pattern was applied before the tensile test. It consists, for the macroscopic samples in a first thin layer, of white paint and a sputtered layer of blue paint on the surface of samples. This creates the artificial image signature. The tensile tests were carrying out until 
breaking of the samples. Tensile direction is defined by $\mathbf{x}$, and $\mathbf{y}$ is perpendicular to $\mathbf{x}$ (see Fig. $5)$.

Time, axial load and axial displacement were recorded by the tensile device software. The nominal stress (First Piola-Kirchhoff tensor) is defined by the following expression:

$$
P=F / S_{0}=F / l_{y} l_{z}
$$

where $F$ is the axial recorded load and $l_{y}, l_{z}$ are the initial useful section dimensions in the $\mathbf{y}$ and $\mathbf{z}$ directions. Nevertheless this definition neglects the cross-sectional area reduction occurring during the loading and the necking. Considering this variation, the true axial stress can be defined by:

$$
\sigma_{\text {true }}=F / S=F / l_{y}^{\prime} l_{z}^{\prime}
$$

where $l_{y}^{\prime}, l_{z}^{\prime}$ are the current section dimensions in the $\mathbf{y}$ and $\mathbf{z}$ directions.

The image processing after the test is based on DIC computation. A two-dimensional digital extensometer is defined in the ROI (Fig. 5). The gauge length has to be small enough to accurately describe the strain gradients in the $\mathbf{x}$ direction, and large enough to evaluate the mean strain in the $\mathbf{y}$ direction. Each point of the virtual mesh corresponds to the centre of a pattern. This pattern, defined by its Correlation size $(\mathrm{Cs}=30$ pixels $=0.96 \mathrm{~mm})$, is the representative area of the material point which is tracked (Fig. 5). Distance between mesh points is given by the Grid step parameter $(\mathrm{Gs}=3$ pixels $=0.096 \mathrm{~mm})$. Deformation calculation is obtained by the first order derivation of the displacement field around the considered point. The dimension of the area where the in-plane gradient tensor is evaluated, is fixed by the number of steps parameter (Ns=4 in the $\mathbf{x}$ direction, $\mathrm{Ns}=20$ in the $\mathbf{y}$ direction,) which qualifies the number of points to take into account in the horizontal and vertical directions. The bidimensional gauge dimensions (GLx and GLy) expressed in pixel and $\mathrm{mm}$, used for different calculations are as follow: GLx=24 pixels $=0.77 \mathrm{~mm}$; GLy $=120$ pixels $=4 \mathrm{~mm}$. It should be noted, that in the $x$ direction, the gauge length estimated by the calculation is smaller than the correlation size (Cs). Also the effective gauge length should be slightly higher than the one estimated. Otherwise the strain gauge is chosen far from the sample boundaries to avoid edge effects $(4 \mathrm{~mm}<6 \mathrm{~mm})$. These correlation parameters have been optimized to establish reliable mechanical response of the material in the central zone where the necking takes place. It may be noted that in order to ensure good local analysis, the longitudinal gauge length is chosen around $1 \mathrm{~mm}$.

The DIC processing leads to an incremental displacement file. In-plane displacements fields $\boldsymbol{u}(x, y)=\left(u_{x}(x, y), u_{y}(x, y)\right)$ of a point $M(x, y)$ were evaluated for each point of a virtual mesh in the ROI of the sample (Fig. 5) which included strain localization area. The calculation of the displacement gradient around a considered point allows the calculation of the two-dimensional displacement gradient tensor $\mathbf{F}$ (eq. 3) and thus the in-plane Green Lagrange strain tensor $\mathbf{E}$ is known for all points defining the ROI of Fig. 5 (eq. 4):

$$
\begin{gathered}
\mathbf{F}(x, y)=1+\nabla \boldsymbol{u}(x, y), \quad \forall M(x, y) \in \mathrm{ROI} \\
\mathbf{E}(x, y)=\frac{1}{2}\left(\mathbf{F}(x, y)^{\mathbf{T}} \otimes \mathbf{F}(x, y)-1\right)=E_{x}(x, y) \mathbf{x} \otimes \mathbf{x}+E_{y}(x, y) \mathbf{y} \otimes \mathbf{y}+E_{x y}(x, y) \mathbf{x} \otimes \mathbf{y}, \forall M(x, y) \in \mathrm{ROI}
\end{gathered}
$$


It is therefore possible to define in-plane strain components of each point defining the ROI domain. Specific points $M_{1}, M_{2}, M_{3}$ and $M_{4}$ are located in the center of the ROI zone and will be useful for further investigations (Fig. 5). Strain cartography of the ROI domain leads to define the point where the maximum strain is reached. This point will be denoted $M_{5}$ and does not necessarily correspond to the point at the minimal section $\left(M_{l}\right)$.

It is useful to define the in-plane stretches ratios in the $\mathbf{x}$ or $\mathbf{y}$ direction:

$$
\lambda_{\mathbf{x}}(x, y)=\frac{l_{x}^{\prime}(x, y)}{l_{x}(x, y)}=\sqrt{2 \mathbf{E}_{\mathbf{x}}(x, y)+1}, \lambda_{\mathbf{y}}=\frac{l_{y}^{\prime}(x, y)}{l_{y}(x, y)}=\sqrt{2 \mathbf{E}_{\mathbf{y}}(x, y)+1}
$$

where $l_{x}(x, y), l_{y}(x, y)\left(l_{x}^{\prime}(x, y), l_{y}^{\prime}(x, y)\right)$ are the initial (current) sections dimensions of the square pattern in the $\mathbf{x}$ and $\mathbf{y}$ directions around $M(x, y)$.

The out-of-plane stretch $\lambda_{\mathbf{z}}(x, y)$ is deduced from the in-plane principal stretches ratios in the longitudinal and transverse direction thanks to a transverse isotropy assumption [22]. This last hypothesis has been validated by some authors for a similar material and in the same range of solicitation [28]. Under this assumption, $S=\lambda_{y}(x, y) \lambda_{z}(x, y) S_{0}(x, y)=\lambda_{y}^{2}(x, y) S_{0}(x, y)$ and Eq. 2 can be rewritten as

$$
\sigma_{\text {true }}(x, y)=F / S_{0}(x, y) \lambda_{y}^{2}(x, y) .
$$

The axial true strain $\varepsilon_{x}$ and nominal strain $\varepsilon_{N}$ are defined by

$$
\varepsilon_{x}(x, y)=\int_{l_{x}}^{l_{x}^{\prime}} \frac{d l(x, y)}{l(x, y)}=\ln \left(\frac{l_{x}^{\prime}(x, y)}{l_{x}(x, y)}\right)=\ln \left(\lambda_{x}(x, y)\right), \varepsilon_{N}(x, y)=\frac{l_{x}^{\prime}(x, y)-l_{x}(x, y)}{l_{x}(x, y)}
$$

\section{Results and discussion}

\subsection{Mechanical properties-global analysis from DIC}

The elastic properties of the samples were first determined from the knowledge of both axial load and true local strain value measured by DIC analysis. For a low level of load, the reversible strain is analyzed all along the longitudinal direction. The Young modulus is therefore computed from eqs. 6 and 7:

$$
E=\frac{\sigma_{\text {true }}(x, y)}{\varepsilon_{x}(x, y)}, \quad \forall M(x, y) \in \mathrm{ROI}
$$

To assess the reliability of Young Modulus identification, four evaluations have been made depending on their positions along the longitudinal axis ( $\mathbf{x}$ direction) (points $M_{1}$ to $M_{4}$ in Fig. 5). For a given time, these points are at the same level of axial load but differ from the values of their current stretches and true stresses. $\lambda_{\mathrm{x}}$ is maximum at point $M_{1}$, associated to the minimal section, and decreases until point $M_{4}$. In fact the behaviour of these points is just shifted in time. As far as we are in the elastic range of strain (between $0.25 \%$ and $0.5 \%$ of axial strain), Young Modulus $(E)$ is almost the same for all the studied points: $1540 \pm 50 \mathrm{MPa}$ (see Fig. 6 for the composite MWCNT (0.1wt\%CNTs without MA). This analysis was repeated 3 times for all the formulations to ensure repeatability. All results are reported in Fig. 7. 
The incorporation of nano charges even at $0.05 \mathrm{wt} \% \mathrm{CNT}$ induces a rise of the Young modulus until $0.5 \mathrm{wt} \% \mathrm{CNTs}$ with and without MA. At $1 \mathrm{wt} \% \mathrm{CNTS}$ the modulus almost reaches the initial value of pure iPP. The initial reinforcement is probably due to good spatial repartition of MWCNTs in the matrix (see section 2.2.1). The effects of CNTs on the crystallization behaviour of PP have been studied by some authors [30-32]. The CNTs served as nucleating agents to enhance crystallization and the crystallites strengthen the composite $[29,33]$. The MA conducts to a lower Young modulus which is incompatible with usual observations [29]: it seems that the spatial dispersion of nanotubes is not improved by the addition of MA (see section 2.2.1) and the better load transfer between polymer matrix and nanotubes produces by MA is not sufficient to improve Young modulus value.

Agglomeration of nanoparticles for higher wt\%CNTs reverses this trend. Similar downturns of the mechanical properties have been observed for composites containing polymergrafted MWCNTs for the same level of incorporation [29]. Moreover, it seems that the percolation threshold is reached at almost the same level of CNTs incorporation with and without MA adding, but some more experiments should confirm this hypothesis.

Micromechanical models can be a good tool to understand this mechanical behaviour. As observed in SEM investigations, MWCNT are individual and randomly distributed under 0.1 wt\%CNTs and agglomerate after that level. Nevertheless these agglomerates seem to be well distributed in the matrix. Mori Tanaka micromechanical model [34] is used to predict Young's modulus of reinforced iPP in both cases. For low level of incorporation, the effective elastic constants of the composite can be expressed as:

$$
\boldsymbol{C}=\boldsymbol{C}_{\boldsymbol{m}}+c_{f}\left\langle\left[\left(\boldsymbol{C}_{f}-\boldsymbol{C}_{\boldsymbol{m}}\right) \boldsymbol{A}_{\boldsymbol{e}}\left(\left(1-c_{f}\right) \boldsymbol{I}+c_{f} \boldsymbol{A}_{e}\right)\right]^{\boldsymbol{I}}\right\rangle
$$

where $\boldsymbol{C}_{\boldsymbol{m}}$ and $\boldsymbol{C}_{f}$ are respectively matrix and fibre stiffness tensor, $c_{f}$ is the volume fraction of fibre, $\boldsymbol{A}_{e}=\left(1+S \boldsymbol{C}_{m}{ }^{-1}\left(\boldsymbol{C}_{f}-\boldsymbol{C}_{\boldsymbol{m}}\right)\right)^{-1}$ where $S$ is the classical Eshelby tensor (for fibrous reinforcement) and $<.>$ is a weighted orientation averaging operator added to consider the arbitrary fibre orientation [35].

To implement this model, Matlab® [36] software was used and appropriate elastic properties of matrix and fibres have been fixed. In [37], a longitudinal Young's modulus (denoted $\mathrm{E}_{\mathrm{L}}$ ) of $600 \mathrm{GPa}$ has been chosen for the MWCNT fibre as a result of a literature review. As the nanotubes are transverse isotropic, four more parameters are necessary to evaluate $\boldsymbol{C}_{\boldsymbol{f}}$ : the transverse Young's modulus (equal to $6 \mathrm{GPa}$ ), the two Poisson's ratio $(0.125$ and 0.3$)$ and the shearing modulus $(2.5 \mathrm{GPa})$, The matrix is also supposed isotropic (Young's modulus of 1.017 $\mathrm{GPa}$ and Poisson's ratio of 0.3$)$ ). The rule of thumb conversion factor of 2:1 is used to convert weight fraction to volume fraction of fibres. In this model, strong assumption of perfect bonding and loading transfer is questionable [38]; for this reason, some authors reduce the effective occupied nanotube volume by $25 \%$ of the initial volume to match experimental data [37]. $c_{f}$ will be therefore replaced by $\alpha^{*} c_{f}$ in the micromechanical implementation, $\alpha$ a constant to be determinated. The first results indicate that for $\alpha=0.26$ Mori Tanaka model well reproduced experimental data for the specimen without MA (see Table 1). At 0.5\%CNTs of weight incorporation, the prediction overestimates the experiments. In fact at this level of incorporation, fibre agglomerates and the model is not applicable (see section 2).

The addition of MA leads to a new identification of parameter $\alpha$ (see Table 1). The smaller effective volume fraction is in accordance with the compatibilisation effect of MA: MA 
does not improve the dispersion as nanotubes are already well dispersed by the process but surrounds the NCTs by a phase softer than the matrix. Therefore the loading transfer decreases which leads to the following smaller equivalent volume of nanotubes.

For higher level of weight fraction, Eq. 9 is revisited to consider agglomeration of fibres. It becomes:

$$
\boldsymbol{C}=\boldsymbol{C}_{\boldsymbol{m}}+\hat{\boldsymbol{c}}_{f}\left[\left(\left\langle\boldsymbol{C}_{f}\right\rangle-\boldsymbol{C}_{\boldsymbol{m}}\right) \hat{\boldsymbol{A}}_{\boldsymbol{e}}\left(\left(1-c_{f}\right) \boldsymbol{I}+\hat{c}_{f} \boldsymbol{A}_{e}\right)\right]^{-1}
$$

where $\boldsymbol{A}_{\boldsymbol{e}}=\left(1+S \boldsymbol{C}_{\boldsymbol{m}}{ }^{-1}\left(\left\langle\boldsymbol{C}_{f}\right\rangle-\boldsymbol{C}_{\boldsymbol{m}}\right)\right)^{-1}$ and $\hat{c}_{f}$ is the volume fraction of agglomerates. In this equation $\left\langle\boldsymbol{C}_{f}\right\rangle$ is the stiffness matrix of agglomerate in which fibres are supposed to be arbitrarily oriented. Thus, the matrix embedded in the agglomerate is neglected. This matrix is therefore isotropic. The same assumption for the effective fibre volume is made and $k_{f}$ is replaced by $\alpha^{*} \mathcal{c}_{f}$ in Eq. 10. We suppose $\alpha=0.21$ and $\alpha=0.26$ for the formulations with and without MA respectively. Results are summarized in Table 2 . The equivalent weight fraction of agglomerates is higher for samples without MA. This result is in accordance with the SEM observation: add MA decreases volume fraction of agglomerates. In all cases the weight fraction of aggregates remains almost the same as the rate of incorporation of nanotubes increases. This analysis deals with a concept of equivalent distribution of nanofillers in the matrix but does not back up to the size distribution of aggregates or agglomerates.

Ultimate properties at the broken section of the sample, ie the strain at break and the tensile strength of the point $M_{5}$ (Fig. 5), are presented in Figs. 8 for all composites. These two parameters are deduced from the local stress-strain curves obtained by DIC and concern the axial true strain and the true maximum stress respectively. If the strain at break is increased with the addition of MA in the absence of nanofiller, this plasticizing effect does not seem to hold whatever the rate of incorporation of CNTs in the composite. Modulation of this observation is still required due to the high dispersion of results break. Much more tangible, the tensile at break follows the same pattern as the Young's modulus with the rate of incorporation of fillers. We first observed an increase of the stress at break with the rate of incorporation of nanofillers, and then a decrease probably due to the poor dispersion of fillers in composites. From this point of view no distinction can be made between composites with or without MA adding.

3.2 Mechanical properties-local analysis

\subsubsection{Strain profiles distribution}

This approach involves the analysis of the onset and growth of necking phenomenon in composite. The idea developed here is to understand how the incorporation and the dispersion of nanofillers affect the phenomenology of rupture of the composite. A first application of this methodology allowed understanding how the incorporation of silica within a polycarbonate could lead in a more homogeneous damage [22]. Strain profiles distributions have been established for different states of stress for iPP and its composites along the longitudinal axis ( $\mathbf{x}$ direction) of the tensile bar and through the necking area (ROI, Fig. 5). A typical result is presented in Fig. 9 for the composite iPP/0.05wt\%CNTs.

These strain profiles have been used to characterize the degree of flatness of each distribution. The shape of the strain profile depends on the formulation: the profile of iPP/MWCNT composites is higher and narrower than the one with MA. To enhance local 
behavior, we introduce a statistical coefficient called flatness coefficient which differentiates a sharp peak from a flat-topped in a non-Gaussian curve:

$$
\boldsymbol{C}_{f}=\frac{\Delta i / h_{\max }}{\left(\Delta i / h_{\max }\right)_{25 M P a}}
$$

where $\Delta i$ is the peak width at half-height, $h_{\max }$ the total height (see Fig. 9) and (.) $)_{25 M P a}$ is the value parameter for $\sigma_{N}\left(M_{1}\right)=25 M P a$. At this level of stress, all the tested specimens follow a homogeneous behavior far away from striction phenomenon. This flatness coefficient traduces the ability of the necking zone to spread over the tensile bar or to be localized in the machined minimal section. An important flatness coefficient indicates a large strain peak meaning a high dissipative energy by plasticity before fracture [22]. This statistical coefficient is plotted (Figs. 10) as a function of axial strain for the point which presents the maximum strain (Point $M_{5}(1.8 \mathrm{~mm}, 0 \mathrm{~mm})$ in Fig. 9). For each formulation 3 samples have been tested. Presented results are an average of these 3 values which presents a very narrow dispersion regardless to the considered property (standard deviation is under $1 \%$ of the mechanical property).

The general evolution is the same for all the tested samples. The flatness coefficient shows a first drop corresponding to the onset of the necking associated to the growth of a strain peak and then, the coefficient stabilizes during the neck propagation.

Under $0.5 \mathrm{wt} \%$ of CNT, the flatness coefficient is always higher when MA is added (see Figs. 10). Maleic anhydride polypropylene has a low surface energy and is expected to give a good compatibility between the CNT and the polymer by formation of stronger linkages in the interfaces and reducing CNTs surface tension. In particular, hydrogen bonding between maleic anhydride grafted PP and CNTs can be observed using infrared spectroscopy [39]. This better load transfer is in accordance with a better strain homogenization observed for all samples under $0.5 \mathrm{wt} \%$ of CNT. The effect on the flatness coefficient of maleic anhydride is reversed beyond $0.5 \%$ of CNTs as illustrated for samples with $0.5 \mathrm{wt} \% \mathrm{CNT}$ (Fig. 10c) and 1wt\%CNT (Fig. 10d). The reason is the particles agglomeration: they are responsible for a great heterogeneity of the strain profile, introducing sometimes a multi-peak strain curve. It is also important to note that the onset of necking does not occur necessarily to the minimal section when aggregates are present in the materials. To illustrate these points strain profiles are plotted for all formulations at same true stress equal to 36Mpa at the broken point (Figs. 11). As shown in Fig. 11a for nonmaleic samples, axial strain profile remains perfectly gaussian under $0.5 \mathrm{wt} \% \mathrm{CNT}$ and became heterogeneous for a higher level of nanofiller incorporations (see samples at $0.5 \mathrm{wt} \% \mathrm{CNTs}$ and $1 w t \%$ CNTs in Fig. 11b). The same kind of evolution is observed for the sample with MA (Figs. 11c-d). In Figure 11b each local peak should therefore correspond to an aggregate: in these cases, with incorporation rate higher than $0.5 \mathrm{wt} \% \mathrm{CNT}$, characterization of local phenomenon via the statistical parameter defined by (11) cannot be a good indicator of the observed phenomenology. As not expected, it is observed that the level of stabilization of the flatness coefficient is higher for higher rates of CNTs (Figs. 11). If this phenomenon is related to the preferential onset of fracture at the aggregate positions it would have been expected that presence of aggregates in composite prevents the necking from propagation. Reverse tendency is observed because several peaks appear from aggregate positions. So others statistical methods should then be established. 
The presence of fillers in the PP matrix increases the flatness coefficient value and so helps the spreading out of the necking area (Figs. 12). On the other hand, for the same flatnesscoefficient value, which defines the shape of the peak, the maximum strain is greater for the composites containing MA. These results confirm the better properties for these last formulations due to a greater accommodation with plasticity.

Samples are loaded in tension, and their behavior before final fracture is analyzed. iPP with $0.05 \mathrm{wt} \% \mathrm{CNT}$ s presents a highly localized neck with a narrow peak. On the other hand, iPP with $0.05 \mathrm{wt} \% \mathrm{CNTs}$ and $5 \mathrm{wt} \% \mathrm{MA}$ presents a more diffuse necking that propagates in both sides of the tensile bar (Fig. 11c). This well corresponds to the strain profiles obtained respectively in Fig.11b and Fig. 11d: a larger peak corresponds to a more important energy dissipated by plasticity.

\subsubsection{Nominal and true stress as a function of maximum longitudinal strain}

Let's now consider the central point $M_{1}$ in Fig. 5. For this point we are able to evaluate both true and nominal strain as a function of axial Green Lagrange component. As the nominal stress (Eq. 1) neglects the cross-sectional area reduction occurring during the necking, it reaches a maximum level and then remains constant or drops. Considering this variation, the true axial stress (Eq. 2) is computed. The evolution of stress-strain until the threshold around $40 \mathrm{MPa}$ is not sensitive to the formulation (Fig. 13a). Moreover incorporation of 0.05 to $0.1 \mathrm{wt} \%$ of MWCNT leads to the maximal reinforcing effect compared with the pure iPP. Increasing of the content of MWCNT above $0.1 \mathrm{wt} \%$ leads to decreasing of the reinforcing effect and especially incorporation of $1 \mathrm{wt} \% \mathrm{CNTs}$ conducts to mechanical properties lower than the pure iPP. This observation is in accordance with the agglomeration phenomenon already observed at this level of incorporation. The same trend is observed for samples with MA but the maximum strain is reduced in all cases: before the peak stress, the mechanical response appears to be independent of the CNT rates (Fig. 13b). This result corroborates the previous result obtained on the evolution of the Young Modulus with CNT content where a smaller variation is obtained with MA content. It seems that the addition of MA around CNT acts as an accommodation agent of the local stress. The stress-strain evolution for sample with higher rate of fillers $(\mathrm{PP}+1 \mathrm{wt} \% \mathrm{CNTs}+5 \mathrm{wt} \% \mathrm{MA})$ is similar to the others except the fact that the fracture is obtained before reaching a maximum stress.

As a conclusion, the results confirm that the better mechanical properties are obtained in the range between 0.05 to $0.1 \mathrm{wt} \% \mathrm{CNTs}$ in iPP without adding of MA compatibilizer with our methodology of fabrication. On the other hand, although weaker mechanical properties are obtained with the addition of MA (with the exception of the pure iPP), the use of MA as compatibilizer, homogenize the mechanical response of nanocomposites that remains the same until the threshold stress of $40 \mathrm{Mpa}$, regardless of the incorporation fraction of CNTs.

\section{Conclusions}

This work investigated the effects of incorporation of carbon nanotubes (CNTs) in polypropylene matrix (PP) on elastic properties and on the onset and growth of necking phenomenon in these composites. 
As a first result, image correlation is diverted from its primary use and leads to the determination of some macroscopic properties as Young modulus, tensile strength and ultimate strain. This true strain value is measured locally by DIC analysis in the necking area. Between 0.05 and $0.5 \mathrm{wt} \% \mathrm{CNT}$ most of these properties (excepted ultimate strain) are improved with the amount of CNTs. Nevertheless the major expected effect of iPP grafted maleic anhydride (better dispersion of nanotubes and an improvement in the load transfer between filler and matrix) is not interesting from a macroscopic point of view in our study: MWCNTs are already well dispersed in the iPP matrix as highlighted by the results obtained from strengthening these materials. The mechanical characterization has shown that both Young modulus and tensile strength of the nanocomposites increase by the addition of nanotubes until $0.5 \mathrm{wt} \% \mathrm{CNTs}$. After that properties decrease with the addition of MWCNTs due to the presence of aggregates, found even when iPPg-MA is added.

The analysis of the onset and growth of necking phenomenon in composite is studied from strain profile distributions. Via a flatness coefficient, this approach provides a means of analysis the plastic dissipative potential before fracture. The local analysis highlights particular behaviour produced by iPP-g-MA. The enhancement of compatibility between CNT and polymer produces a strain homogeneization: striction in the central area of the sample is either the source of local breaking (neat iPP) or the origin of spreading through the sample (iPP-g-MA). Furthermore, these results reveal the benefits of anhydride maleic with regards to dissipative energy phenomena.

Finally this integrated local approach may be followed to introduce an energy analysis of the fracture of these heterogeneous materials by using numerical tool such as finite element modeling. Also instrumented tests in SEM should validate the phenomenology of deformation observed.

\section{Acknowledgements}

This work was supported by grant COST Action MP0701 given to Dr. E. Ivanov for a research visit at Ecole des Mines d'Alès, Alès, France. The authors acknowledge the collaboration with Dr Sossio Cimmino, Dr. Clara Silvestre and Dr. Donatella Duraccio (ICTP-CNR, Pozzuoli, Italy) for the optical micrographs.

\section{References}

[1] Du JH, Bai J, Cheng HM. The present status and key problems of carbon nanotube based polymer composites. Express Polym Lett 2007;1:253.

[2] Coleman JN, Khan U, Gun'ko YK. Mechanical reinforcement of polymers using carbon nanotubes. Adv Mater 2006;18:689.

[3] Moniruzzaman M, Winey KI. Polymer nanocomposites containing carbon nanotubes. Macromolecules 2006;39:5194.

[4] Lin Y, Meziani MJ, Sun YP. Functionalized carbon nanotubes for polymeric nanocomposites. J Mater Chem 2007; 17:1143.

[5] López Manchado MA, Valentini L, Biagiotti J, Kenny JM. Thermal and mechanical properties of single-walled carbon nanotubes-polypropylene composites prepared by melt processing. Carbon 2005;43(7):1499-505. 
[6] Kashiwagi T, Grulke E, Hilding J, Groth K, Harris R, Butler K, et al. Thermal and flammability properties of polypropylene/carbon nanotube nanocomposites. Polymer 2004;45(12):4227-39.

[7] Zhang QH, Rastogi S, Chen DJ. Low percolation threshold in single-walled carbon nanotube/high density polyethylene composites prepared by melt processing technique. Carbon 2006;44(4):778-85.

[8] Xiao KQ, Zhang LC, Zarud I. Mechanical and rheological properties of carbon nanotubereinforced polyethylene composites. Compos Sci Technol 2007;67:177-82.

[9] Meincke O, Kaempfer D, Weickmann H, Friedrich C, Vathauer M, Warth H. Mechanical properties and electrical conductivity of carbon-nanotube filled polyamide- 6 and its blends with acrylonitrile/butadiene/styrene. Polymer 2004;45(3):739-48.

[10] Lee SH, Kim MW, Kim SH, Youn JR. Rheological and electrical properties of polypropylene/MWCNT composites prepared with MWCNT masterbatch chips. Euro Polym J 2008;44(6):1620-30.

[11] Park WK, Kim JH. Effect of carbon nanotube pre-treatment on dispersion and electrical properties of melt mixed multi-walled carbon nanotubes/ poly(methylmethacrylate) composites. Macromol Res 2005;13(3):206-11.

[12] Song YS, Youn JR. Influence of dispersion state of carbon nanotubes on physical properties of epoxy nanocomposites. Carbon 2005;43(7):1378-85.

[13] Song YS, Youn JR. Modeling of effective elastic properties for polymer based carbon nanotube composites. Polymer 2006;47(5):1741-8.

[14] Wang Y, Wu J, Wei F. A treatment method to give separated multi-walled carbon nanotubes with high purity, high crystallization and a large aspect ratio. Carbon 2003;41:2939-48.

[15] Eitan A, Jiang K, Dukes D, Andrews R, Schadler LS. Surface modification of multiwalled carbon nanotubes: toward the tailoring of the interface in polymer composites. Chem Mater 2003;15:3198-201.

[16] Kotsilkova R. Thermosetting nanocomposites for engineering application. Rapra Smiths Group, UK, 325 p. (2007).

[17] Kotsilkova R, Ivanov E, Krusteva E, Silvestre C, Cimmino S, Duraccio D. Isotactic polypropylene composites reinforced with multiwall carbon nanotubes. Part. 2. Thermal and mechanical properties related to the structure. J. of Appl. Polymer Sci. 2010;115: 3576-3585.

[18] Blond D, Barron V, Reuther M, Ryan KP, Nicolosi V, Blau WJ, et al. Enhancement of modulus, strength and toughness in poly(methyl methacrylate)-based composites by the incorporation of poly(methyl methacrylate)-functionalized nanotubes. Adv Funct Mater 2006; 16:1608.

[19] Hwang GL, Shieh YT, Hwang KC. Efficient load transfer to polymer-grafted multiwalled carbon nanotubes in polymer composites. Adv Funct Mater 2004;14:487.

[20] Shi JH, Yang BX, Pramoda KP, Goh SH. Enhancement of the mechanical performance of poly(vinyl chloride) using poly(n-butyl methacrylate)-grafted multiwalled carbon nanotubes. Nanotechnology 2007;18:375704.

[21] Wang M, Pramoda KP, Goh SH. Enhancement of the mechanical properties of poly(styrene-co-acrylonitrile) with poly(methyl methacrylate)-grafted multiwalled carbon nanotubes. Polymer 2005;46:11510. 
[22] Christmann A, Ienny P, Quantin J.C, Caro-Bretelle A.S, Lopez-Cuesta J.M. Mechanical behavior at large strain of polycarbonate nanocomposites during uniaxial tensile test. Polymer 2011;52:4033-4044.

[23] Bing Pan, Kemao Qian, Huimin Xie and Anand Asundi. Two-dimensional digital image correlation for in-plane displacement and strain measurement: a review. Meas. Sci. Technol. 2009;20(6):062001, 17pp.

[24] Ienny P, Caro-Bretelle AS, Pagnacco E. European Journal of Computational Mechanics 2009; 18(3-4):353-376.

[25] Avril S, Bonnet M, Bretelle AS, Grédiac M, Hild F, Ienny P, Latourte F, Lemosse D, Pagano S, Pagnacco E, Pierron F. Experimental Mechanics 2008; 48(4):381-402.

[26] Lee G.W., Jagannathan S., Chae H.G., Minus M.L., Kumar S. Polymer 2008; 49:18311840.

[27] Caro-Bretelle A.S.B., Ienny P., Nait-Ali L.K., Bergeret A. Strain. 2012, In Press.

[28] Le Cam J.B., Toussaint E. Mechanics of Materials 2009; 41:898-901.

[29] Yang B.X, Shi J.H, Pramoda K.P, Goh S.H. Composite Science and Technology 2008; 68:2490-2497.

[30] Zhou Z., Wang S., Zhang Y., Zhang Y.X. J. Appl. Polym. 2006 ; 102 :4823-4830.

[31] Seo M.K., Lee J.R., Park S.J. Material Science and Engineering 2005; 404:79-84.

[32] Grady B.P., Pompeo F., Shambaugh R.L., Resasco D.E. J. Phys. Chem. B 2002; 106: $5852-5858$.

[33] Coleman J.N., Cadek M., Blake R., Nicolisi V., Ryan K.P., Belton C. et al. Adv. Funct. Mater. $2004 ; 14$ : 791-796.

[34] Mori T, Tanaka K. Acta Metallurgica 1973; 21:571- 574.

[35] Schjodt-Thomsen J, Pyr R. Mechanics of Materials 2001; 33:531-544.

[36] Besson J, Leriche R, Foerch R, Cailletaud G, Revue europpéenne des éléments Finis 1998; 7:567-588.

[37] Eitan A., Fisher F.T., Andrews R., Brinson L.C., Schadler L.S. Composites Science and Technology 2006; 66:1162-1173.

[38] Pantano A, Modica G., Cappello F. Materials Science and Engineering A 2008; 486:222227.

[39] Lee S.H., Cho E., Jeon S.H., Youn J.R. Carbon 2007; 45: 2810-2822.

[40] Bikiaris D. Materials 2010; 3:2884-2946. 

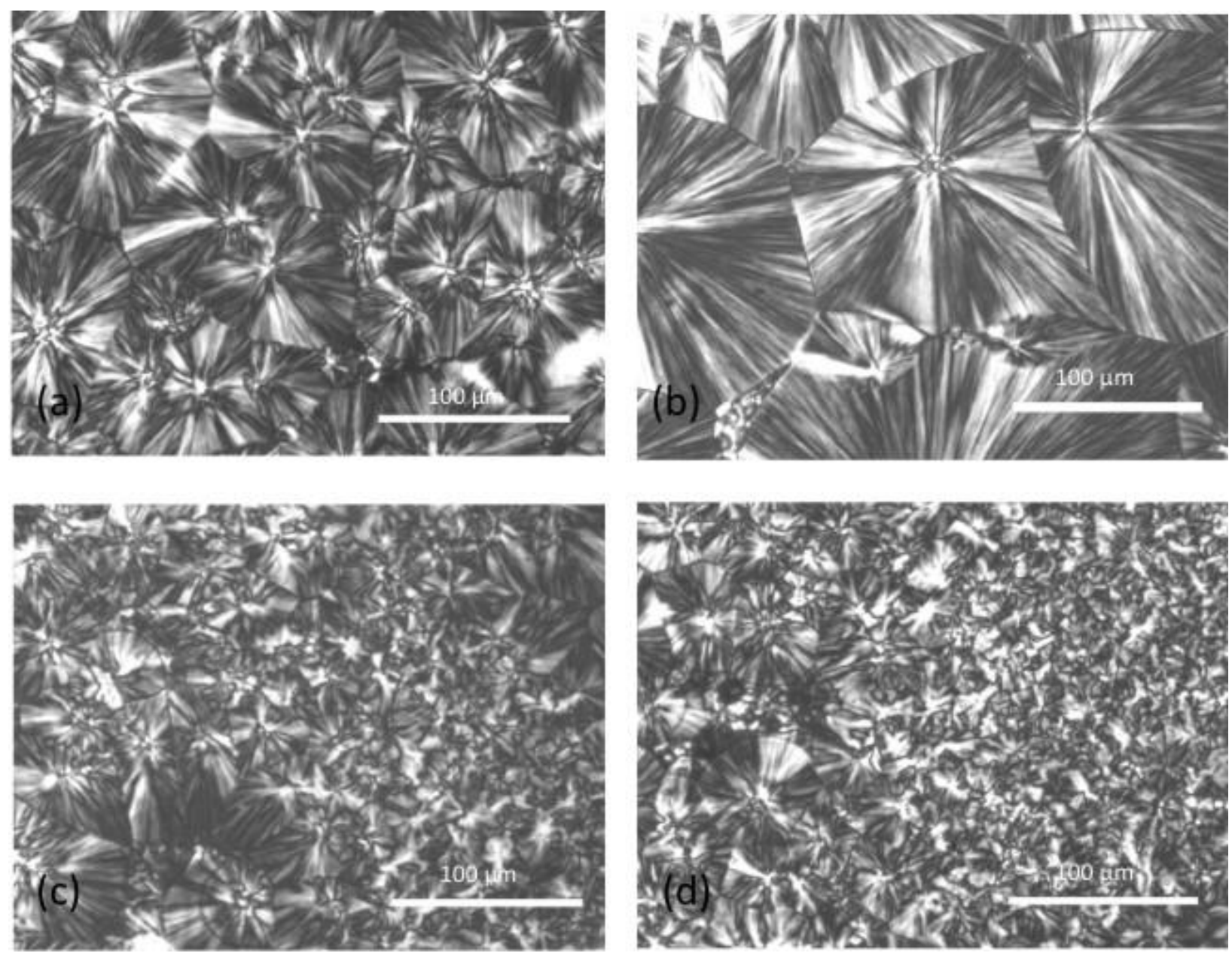

Figure 1. Optical micrographs of iPP (a) and iPP-g-MA (b), (c), (d) 

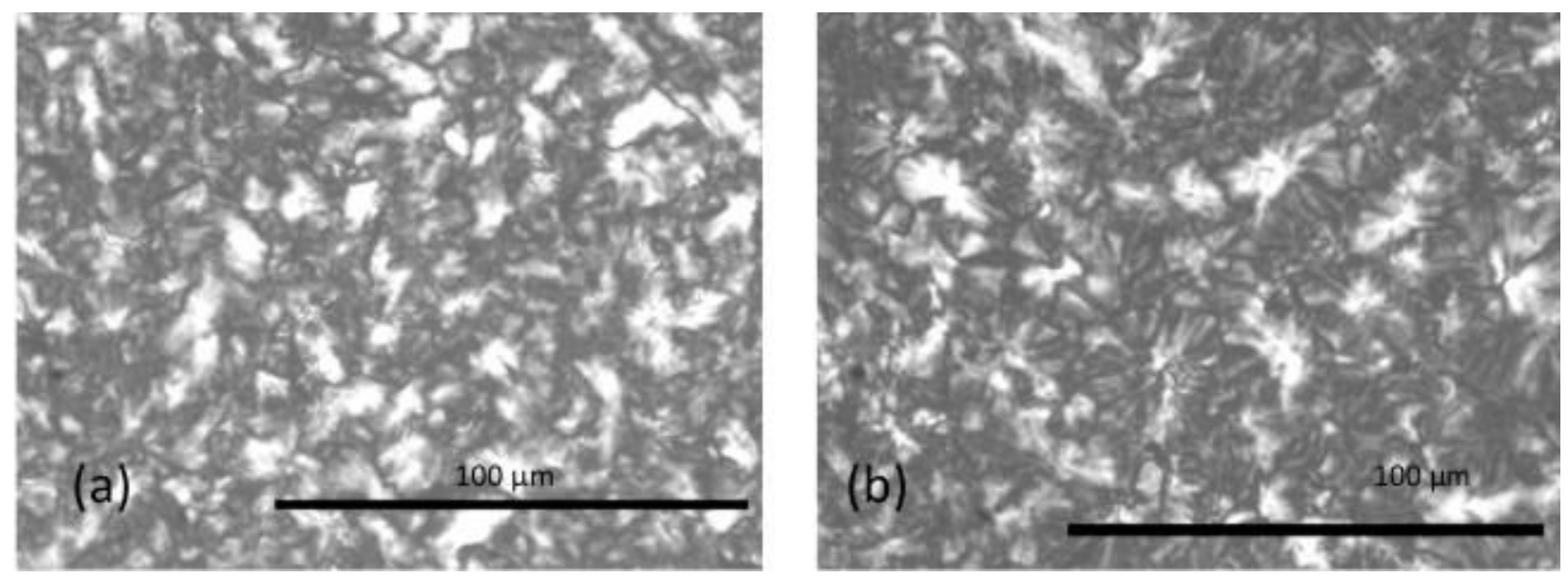

Figure 2 Optical micrographs of iPP/0.05wt\%CNTs (a) and iPP/0.05wt\% CNTs+5\% MA-g-iPP composites (b) 

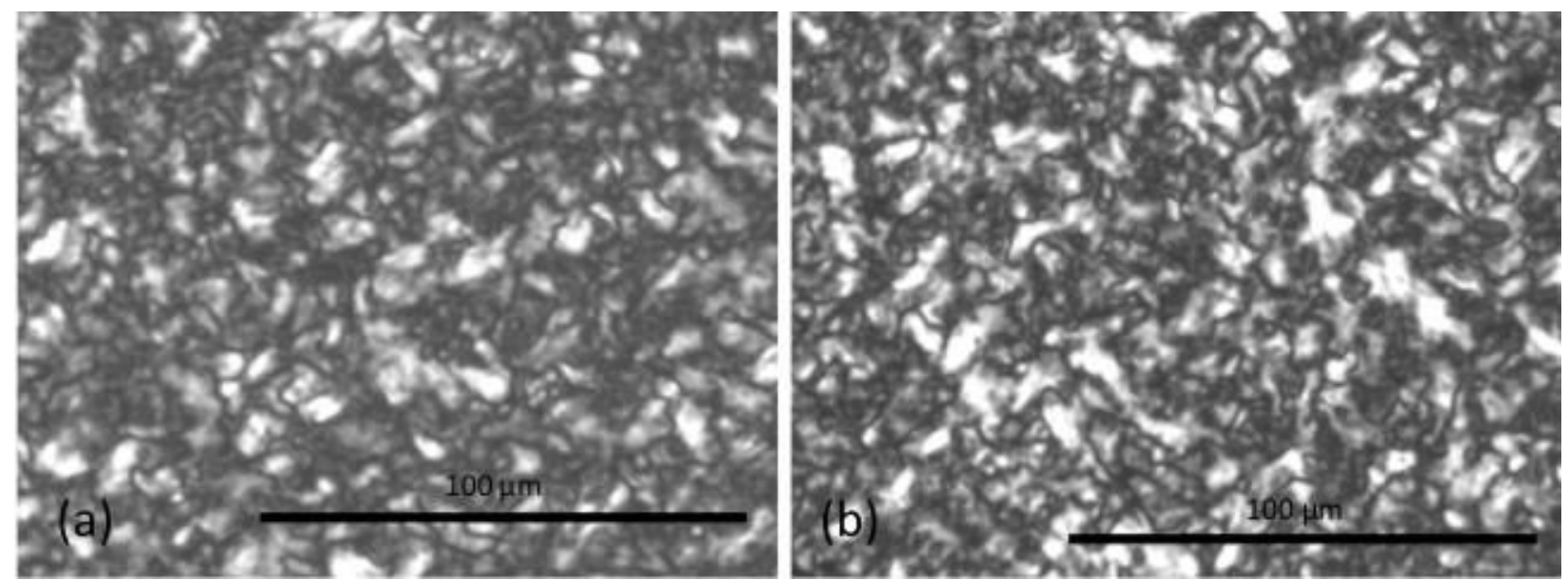

Figure 3. Optical micrographs of iPP/0.1wt\% CNTs (a) and iPP/0.1wt\% CNTs +5\% MA-g-iPP composites (b) 

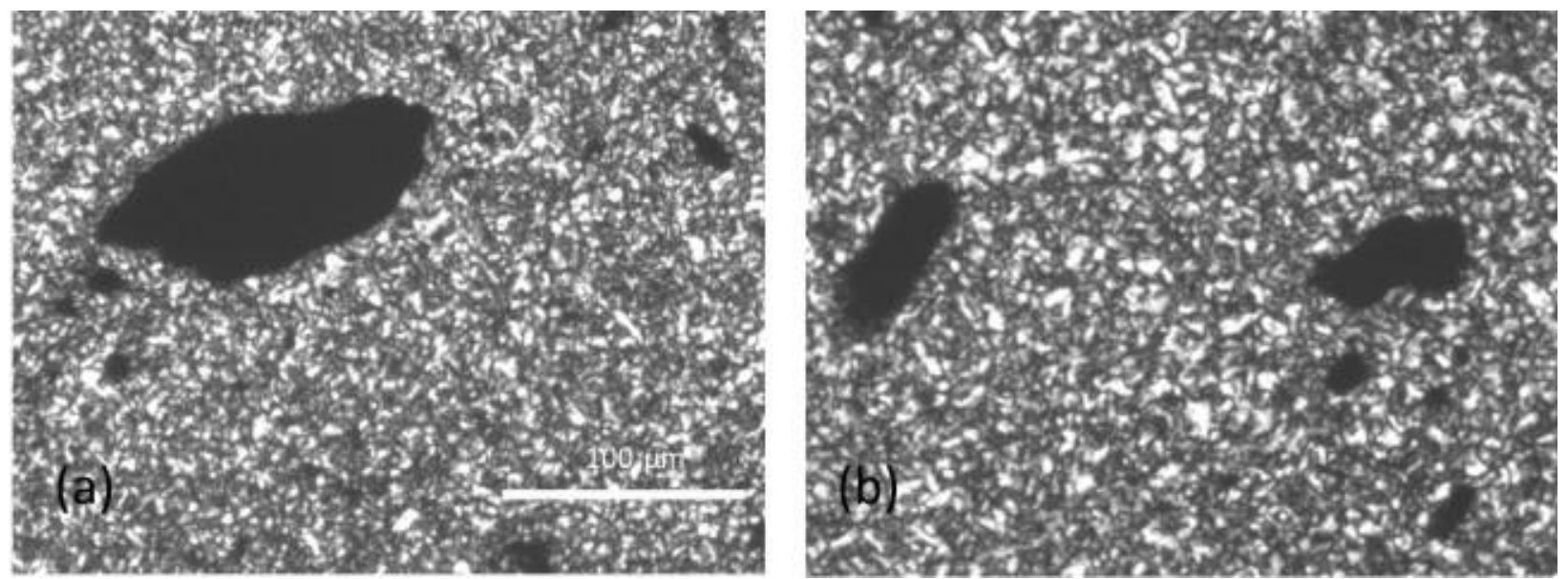

Figure 4. Optical micrographs of iPP/1wt\% CNTs (a) and iPP/1wt\% CNTs composites+5\% MA-g-iPP (b) 


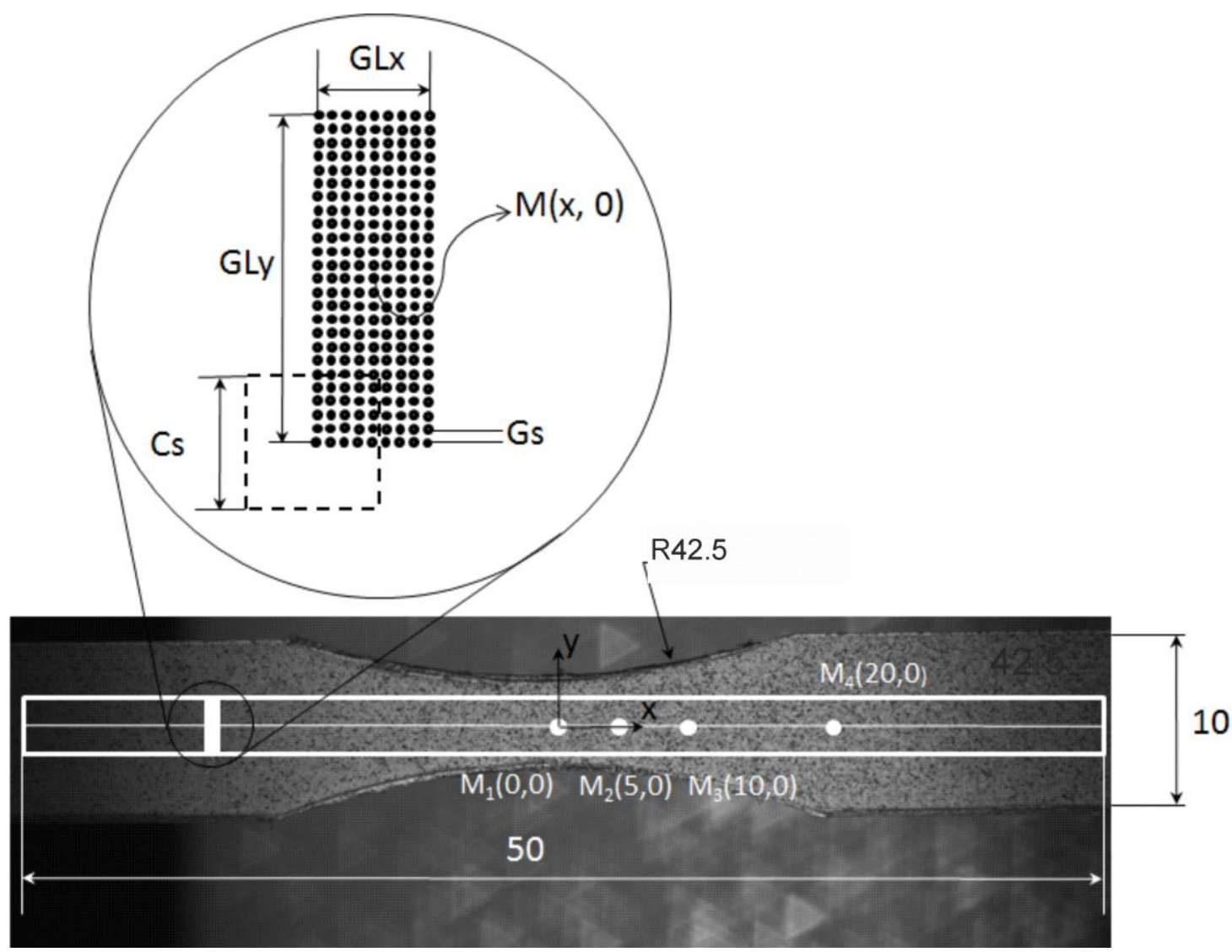

Figure 5. Geometries of the hourglass specimens (quotations in $\mathbf{m m}$, $\mathbf{R}$ radius of curvature), thickness between 0.4 to $1 \mathrm{~mm}$ 


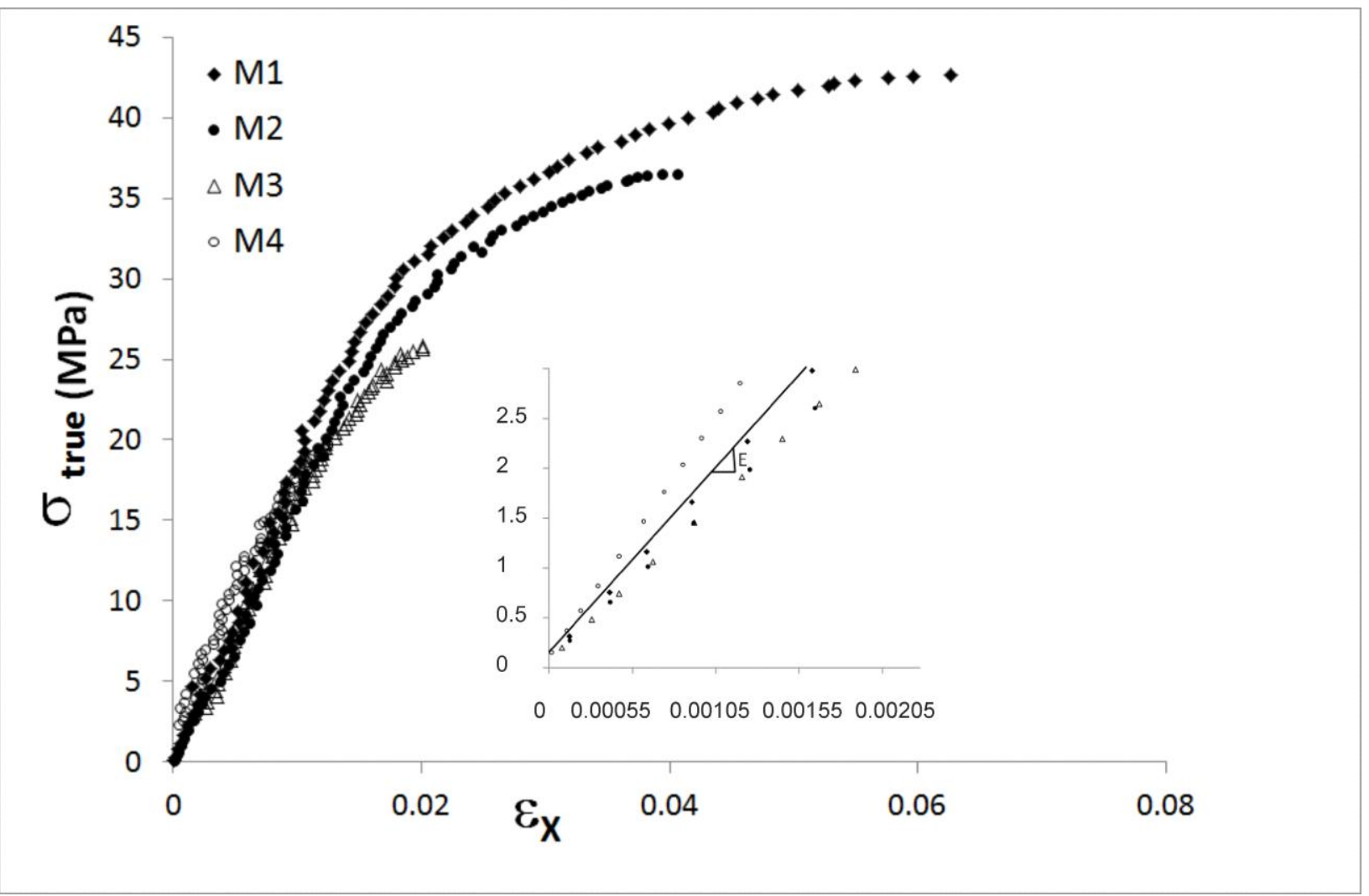

Figure 6. Stress-strain behaviour of iPP/0.05wt\% CNTs from DIC measurements 


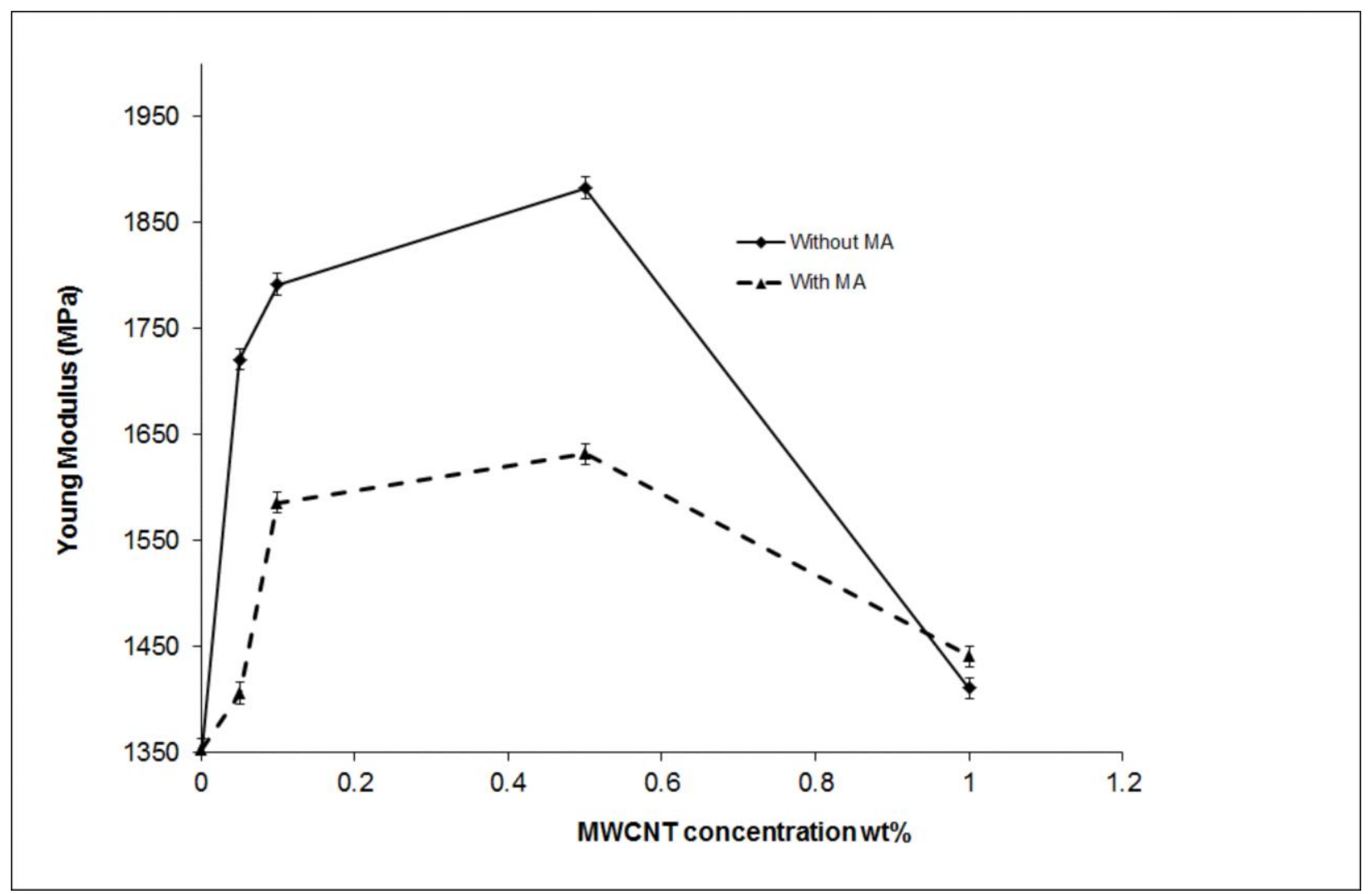

Figure 7. Normalized values of Young Modulus as functions CNT content 

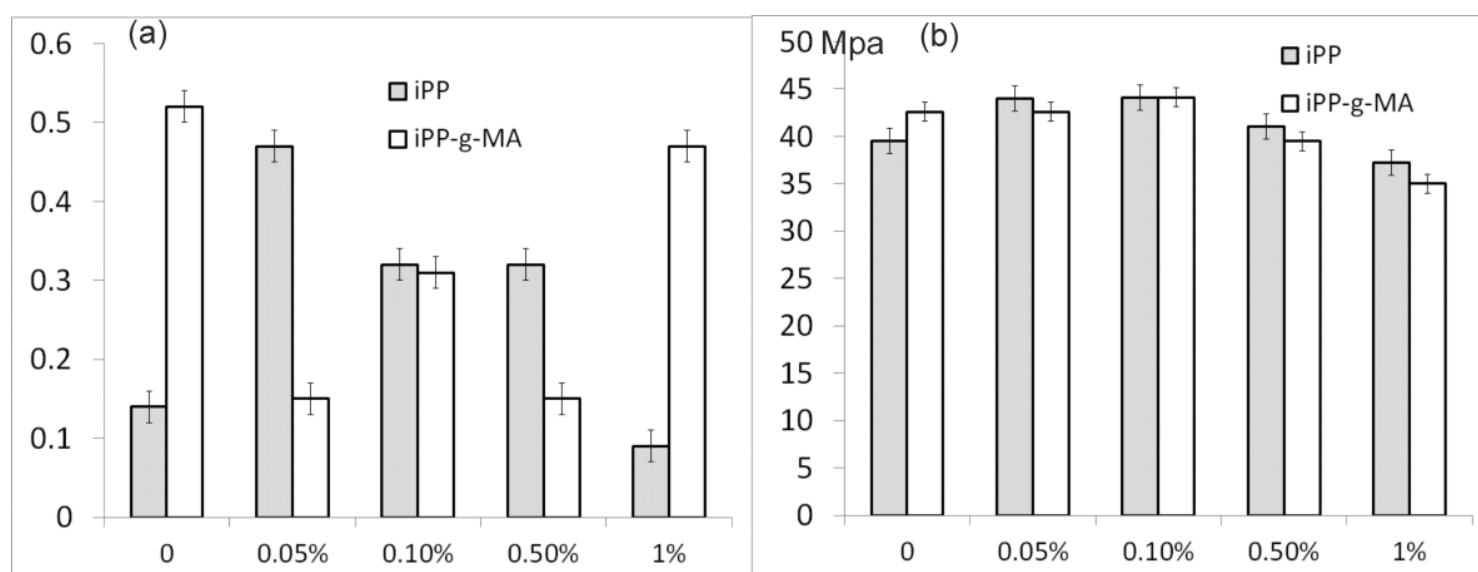

Figure 8. Strain at break (a) tensile strength (b) for different CNT content in MWCNTs composites with and without MA evaluated in the broken section of the sample (point $M_{5}$ ) 

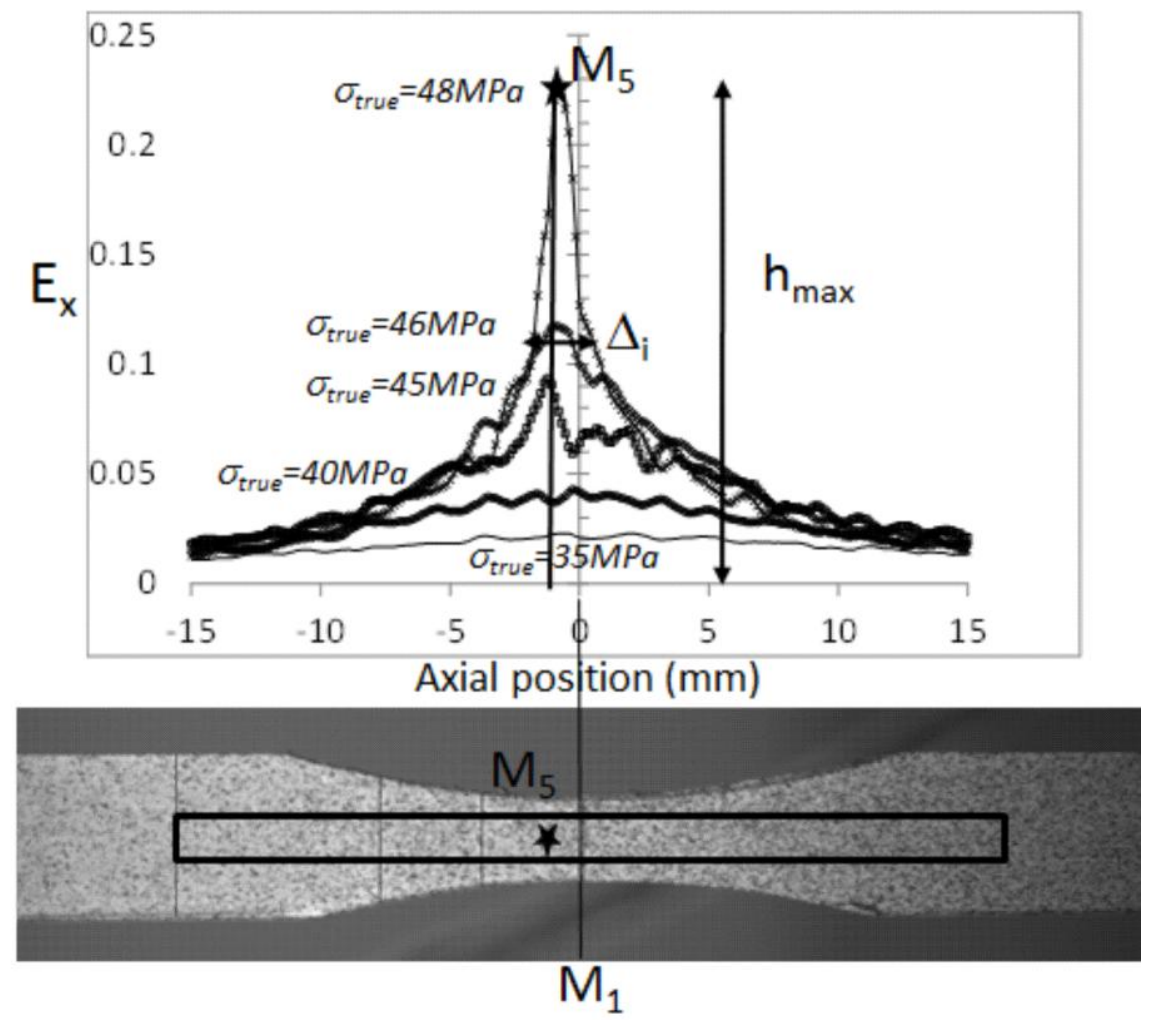

Figure 9 - Strain profile distributions for the iPP/0.05wt\% CNTs composite 

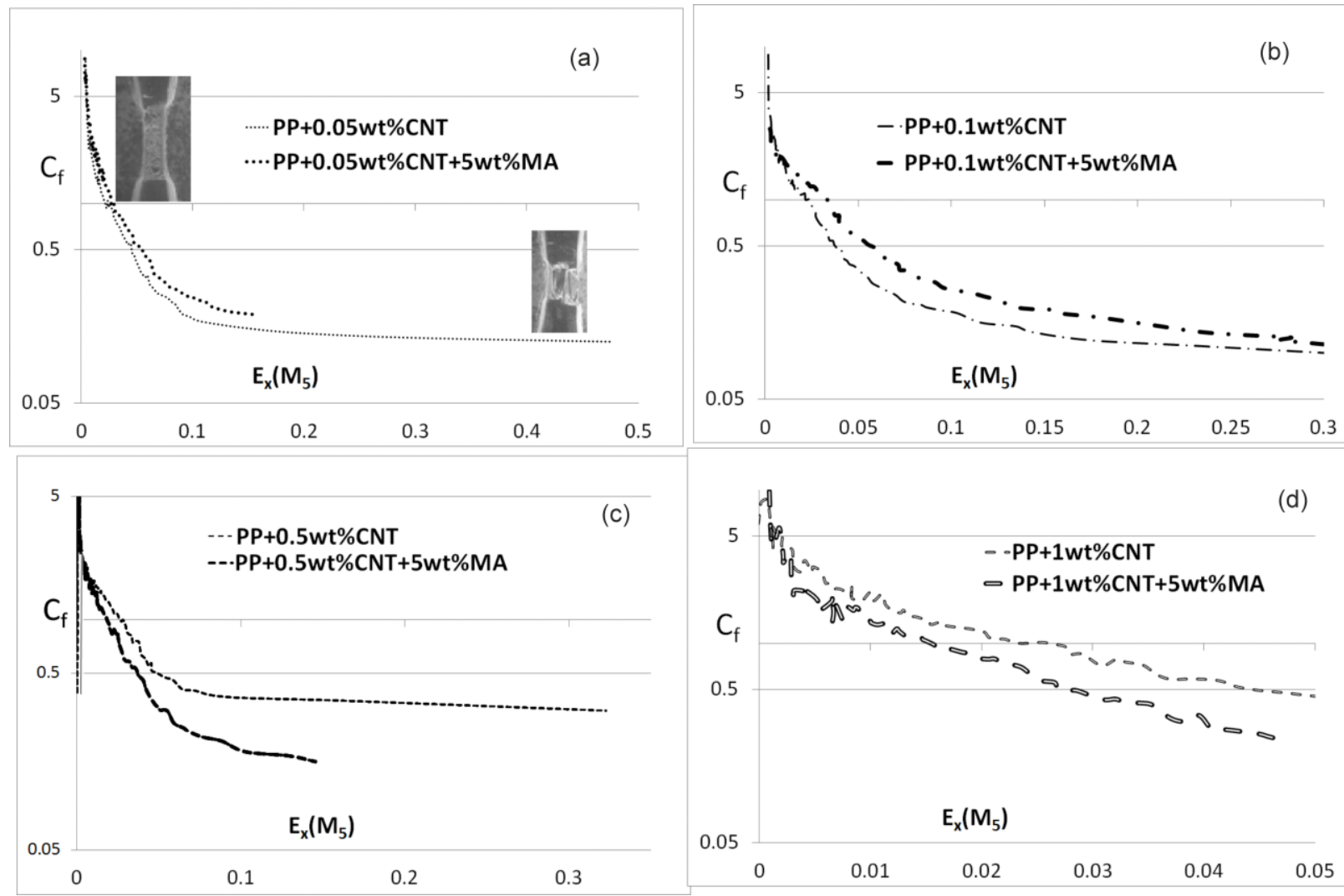

Figure 10 - Flatness coefficient as a function of $E_{x}\left(M_{5}\right)$ for the iPP/0.05wt $\%$ CNTs composite (a), for the iPP/0.1wt \% CNTs composite (b), for the iPP/0.5wt\% CNTs composite (c) and for the iPP/1wt \% CNTs composite (d) with and without MA 


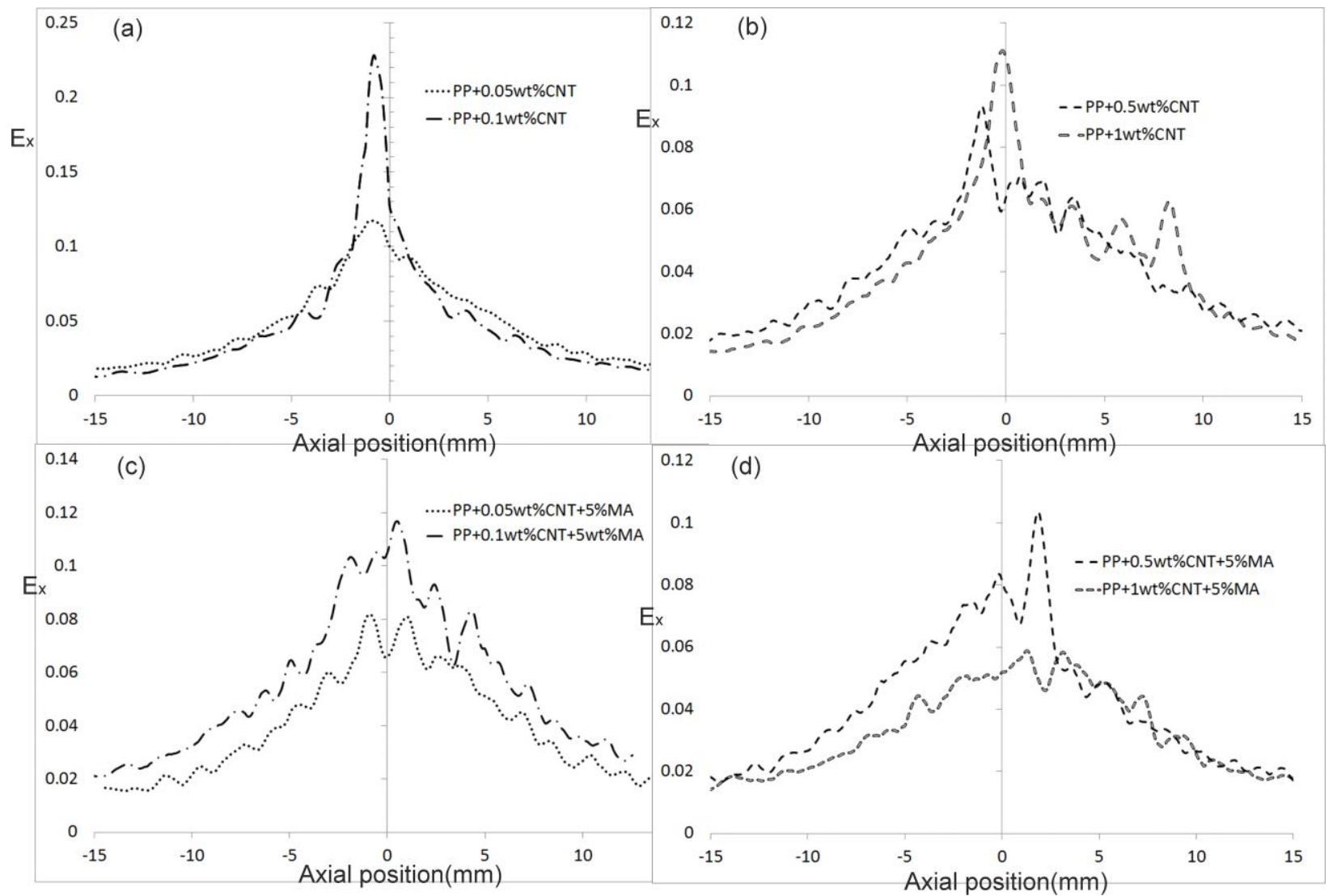

Figure 11 - Strain profile distribution at $\sigma_{\text {true }}\left(M_{5}\right)=36 \mathrm{MPa}$ of the stress level for the iPP/0.05-0.1wt $\%$ CNTs composite (a), for the iPP/0.5-1wt\% CNTs composite (b) without MA and for the iPP/0.05-0.1wt\% CNTs composite (c), for the iPP/0.5-1wt\% CNTs composite (d) with MA 

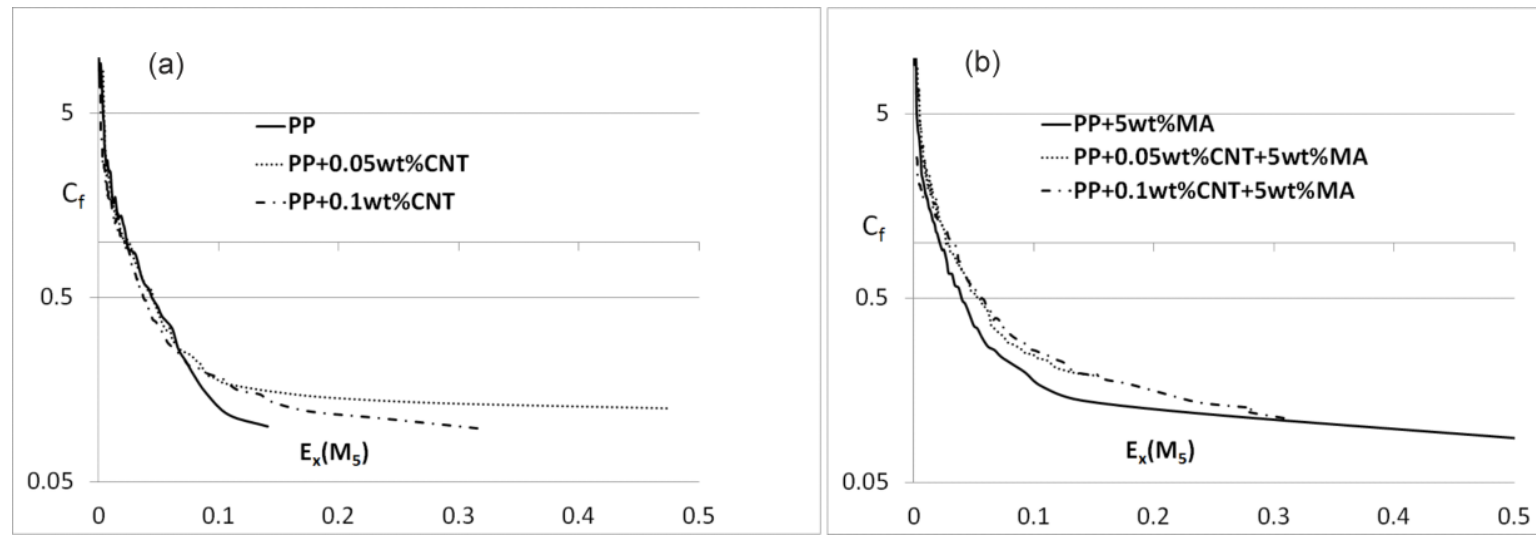

Figure 12 - Flatness coefficient as a function of $E_{x}\left(M_{5}\right)$ without (a) and with MA (b) 


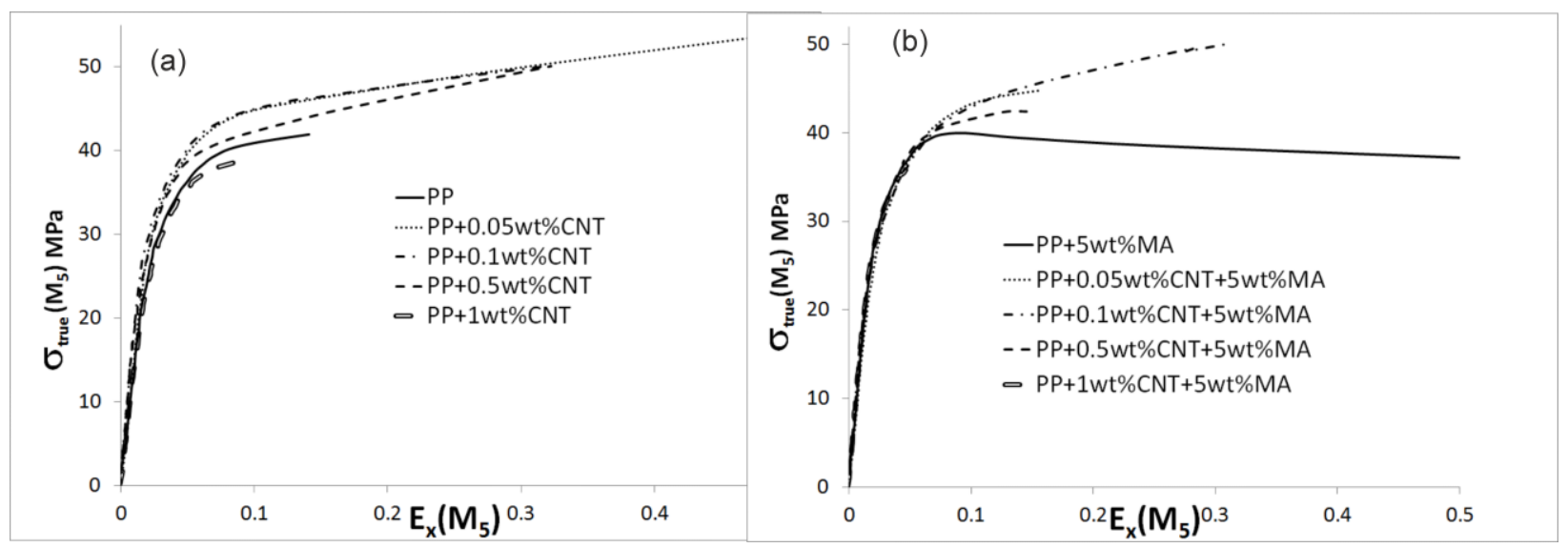

Figure 13 - True stress as a function of axial strain for iPP and its composites without (a) and with MA (b) evaluated for the point $M_{5}$ 


\begin{tabular}{|l|l|l|l|l|}
\hline $\mathrm{wt}(\%)$ & $\mathrm{MAwt}(\%)$ & $\alpha$ & $\mathrm{E}_{\mathrm{L}}$ (model) $\mathrm{GPa}$ & $\begin{array}{l}\mathrm{E}_{\mathrm{L}} \text { (experiments) } \\
\mathrm{GPa}\end{array}$ \\
\hline 0.05 & 0 & $26 \%$ & 1.71 & 1.72 \\
\hline 0.1 & 0 & $26 \%$ & 1.79 & 1.79 \\
\hline 0.5 & 0 & $26 \%$ & 3.45 & 1.88 \\
\hline 0.05 & 5 & $21 \%$ & 1.41 & 1.40 \\
\hline 0.1 & 5 & $21 \%$ & 1.59 & 1.59 \\
\hline
\end{tabular}

Table 1: Experimental and fitted Young's modulus as a function of weight concentration 


\begin{tabular}{|l|l|l|}
\hline CNT wt(\%) & MA wt(\%) & Aggregates wt(\%) \\
\hline 0.5 & 0 & $11 \%$ \\
\hline 0.5 & 5 & $6 \%$ \\
\hline 1 & 0 & $10 \%$ \\
\hline 1 & 5 & $5 \%$ \\
\hline
\end{tabular}

Table 2: Weight fraction of aggregates as a function of weight concentration of CNT and MA. 